\title{
Invited commentary on Rethinking funding priorities in mental health research ${ }^{\dagger}$
}

\author{
Kamaldeep Bhui
}

\begin{abstract}
Summary
This commentary takes up the notion proposed by Lewis-Fernández and colleagues that we need more balance in research priorities. Specifically, our reliance on neurobiology may be misplaced and likely to be unrewarding unless we ensure that: (a) research with better return for patients and the public is also pursued; (b) research findings are put into practice; and (c) we retain a focus on proportionate investment in service provision. Patient, public and economic perspectives should drive the decision making for better investment, and behaviour change might be better targeted at commissioners and policy makers rather than patients and providers.
\end{abstract}

\section{Declaration of interest.}

K.B. is Editor of the BJPsych, a former Public Health Lead of the Royal College of Psychiatrists, and his research areas are in cultural, environmental and social psychiatry. He is Director of the MSc Cultural and Global Perspectives in Mental Healthcare and Psychological Therapies, Co-Director on the MSc Mental Health and Law, and Co-Director on the MSc Creative Arts and Mental Health and the Professional Doctorate in Intercultural Psychoanalytic Psychotherapy. $\mathrm{He}$ is a Trustee of Careif, an international mental health charity.

\section{Copyright and usage}

(C) The Royal College of Psychiatrists 2016. This is an open access article distributed under the terms of the Creative Commons Non-Commercial, No Derivatives (CC BY-NC-ND) licence.
Lewis-Fernández et al call for more balance between neurobiological and other research areas, as part of a strategic approach to tackle mental illnesses. They propose a more intellectually robust portfolio of research and allocated funds in the USA and other high-income countries. The purpose is to optimise the chances of a return on the investment in terms of indices of effective patient care and population outcomes. The National Institute of Mental Health (NIMH), under the leadership of Thomas Insel, powerfully steered national and international researchers, policy makers and research commissioners to buy into a hopeful dream that one day the basic sciences will afford opportunities to prevent and treat mental illness at its root cause. Much like efforts to try and prevent cancer, cardiovascular disease, dementia and Parksinson's disease, a molecular and genetic understanding of mechanisms opens up fresh possibilities including biological and pharmacological targets. ${ }^{1,2}$ The emphasis on personalised medicine, including exciting and hope-giving prospects afforded by advances in connectomics and genomics, demands a level of precision in diagnostic and mechanistic profiling that we have yet to see. ${ }^{3}$ What is driving the search for the radical cures for mental illnesses in the biology and structures of the brain over and above the way services are organised and delivered?

The limited progress in finding root causes and new treatments for mental illness, concerns about stigma related to uniquely societal rather than biomedical causes, concerns that mental illness is not seen as a disease/illness but a social consequence of poor living conditions, and abundant opportunities consequent upon the progress in mapping the human genome all came together requiring a new ambition: that of more cost-effective treatments targeting the root biomedical causes of mental disorders as disease entities, rather than the perceived social causes and consequences more closely associated

†See editorial, pp. 507-509, this issue. with illness entities closer to patients' experience. By contrast, cancer or heart diseases are not seen as having poor status, as less worthy or as competing disease or illness categories, despite the emphasis on prevention through changes in diet, exposure to carcinogens, environmental and lifestyle behaviours. Tackling the social and behavioural determinants of mental illnesses might promote better outcomes, and they are as much a part of pathogenesis as the molecule or gene. Perhaps, the polarisation of the neurobiological $v$. the cultural, environmental, and social is at the heart of the imbalance in perspective that Lewis-Fernández and colleagues seek to remedy.

In the UK, mental illnesses affect $23 \%$ of the population at any one time, and over the life course, the majority of people will experience emotional distress that needs some sort of intervention. In the UK, mental illness costs $\mathfrak{£} 105$ billion a year in total societal and economic terms, and $£ 105$ million a year is spent on research, largely funded by the Wellcome Trust, the Medical Research Council, and the National Institute for Health Research. ${ }^{4,5}$ A recent survey by MQ, a new mental health charity, found that $5.5 \%$ of the UK research budget is spent on mental illness compared with $19.6 \%$ for cancers; per person affected,

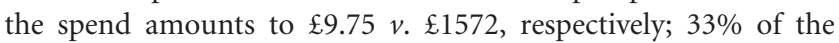
annual research spend for mental illnesses is on underpinning brain sciences, although the balance is more favourable in the UK (about 33\% v. 85\% in the US towards neurobiological research).

To realise a societal return on investment, and improvements in prevention and treatment, research programmes will need to be reflective of the granularity and complexity of mental illnesses. We need a far better grasp on the broad range of mental illnesses, from schizophrenia to depression, to autism, to stress-related disorders such as post-traumatic and occupational disorders, whether in the hospital or clinical setting, or in the population at large. Will brain sciences improve outcomes equally across these diagnostic groups?

The relative contributions of genes, neurodevelopmental and intellectual vulnerabilities, and the powerful impact of adverse 
experiences and epigenetic phenomena, are now better understood. Such developments need better-trained and better-informed doctors, scientists and public health experts, not to mention greater levels of knowledge for every citizen so that the social campaign to tackle mental illness amplifies scientific endeavours. ${ }^{6}$ In the UK, financial constraints have led to a drop in the volume of services, raising questions about what is a priority: ${ }^{4}$ futureproofing a research aspiration or immediate care of those most in need. The National Institute of Health Research (UK) emphasises in its commissioning briefs that patients and the public must be involved in research and that they must see benefit within a 3- to 5-year time-frame, an aspiration that neurobiological research may struggle to meet. Although separate funding bodies may then start to champion different types of research endeavour, surely the pattern of commissioning should be more reliant on evidence of public health impacts and benefits for individuals and families, and costs to society.

Furthermore, even when research findings promise definitive impacts, translating these into policy and practice realities seems to need a different sort of science: implementation science and the science of co-creation for more impactful commissioning and policy. ${ }^{7,8}$ Co-creation of interventions, apart from democratising the research process, reduces translational gaps by enhancing interventions so they are ready for implementation. Tackling stigma, and promoting public education and agency and better health structures for delivering care of quality and compassion, seem as important an immediate priority as investing in the future of neurobiological research. Research commissioners should commission public, patient and economically driven evaluations of their research programmes, and balance their portfolios accordingly.

Despite being an area of incredible needs and expressed priority for societal wellness and success, the complexity of mental illness and the challenges of finding effective interventions seem to be unattractive for research councils, charities and the public, all seeming to favour other types of disease/illness. More research on comorbidities, severe and multiple disadvantages, and the syndemics of disease and illness are needed, and will likely show that societal and professional division of priorities into separate mental and physical is unworthy, is not scholarly and does a disservice to patients and the public. Positive promises of more funding from the UK government have seen little investment trickle into frontline provision of care for people with mental illnesses. Even the prize of societal resilience and reducing inequalities that might follow the targeting of cultural and social determinants, and more preventive interventions, lacks business plans, substance and investment. A better grasp of the neurobiology of political promises will not help us with these dilemmas; success must focus on better knowledge, and greater levels of motivation and capabilities leading to behaviour change among commissioners, policy makers, practitioners and patients - and researchers.

Kamaldeep Bhui, MD, Wolfson Institute of Preventive Medicine, Old Anatomy Building, Charterhouse Square, London EC1M 6BQ, UK. Email: k.s.bhui@qmul.ac.uk

First received 5 Apr 2016, accepted 18 Apr 2016

\section{References}

1 Imming $\mathrm{P}$, sinning $\mathrm{C}$, Meyer $\mathrm{A}$. Drugs, their targets and the nature and number of drug targets. Nat Rev Drug Discov 2006; 5: 821-34.

2 Insel TR, Voon V, Nye JS, Brown VJ, Altevogt BM, Bullmore ET, et al Innovative solutions to novel drug development in mental health. Neurosci Biobehav Rev 2013; 37: 2438-44.

3 Bhui K. From the Editor's desk. Br J Psychiatry 2015; 207: 467-68.

4 Campion J, Bhui K, Bhugra D. European Psychiatric Association (EPA) guidance on prevention of mental disorders. Eur Psychiatry 2012; 27: 68-80.

5 MQ Transforming Mental Health. Mental Health Research Funding Landscape Report (http://www.joinmq.org/research/pages/mental-health-researchfunding-landscape-report). MQ, 2015.

6 Bhui K. Ahead in mental sciences: cultural, environmental and social campaigns. Br J Psychiatry 2016; 208: 407-8.

7 Oliver K, Lorenc T, Innvaer S. New directions in evidence-based policy research: a critical analysis of the literature. Health Res Policy Syst 2014; 12: 34 .

8 Oliver K, Innvar S, Lorenc T, Woodman J, Thomas J. A systematic review of barriers to and facilitators of the use of evidence by policymakers. BMC Health Services Res 2014; 14: 2. 